\title{
Comparison of two clinical decision support systems for analysis of Potential Drug-Drug Interactions prevalent in ICU
}

Rebeca Stahlschmidt (IC), Aline T. Rodrigues (PG), Patricia Moriel (PQ), Priscila G. Mazzola (PQ)

\begin{abstract}
Intensive Care Unit patients have an extensive medication order which contributes to potential adverse events occurring due to Drug-Drug Interactions. This study aims to compare two clinical decision support systems that are databases constantly uptated that contain information about the drugs and interactions among them.
\end{abstract}

Key words: Potencial Drug-Drug Interactions, Clinical Decision Support Systems, Intensive Care Unit .

\section{Introduction}

Potential Drug-Drug Interactions (PDDIs) are pharmacological or clinical responses to the administration of two or more drugs that are different from the response triggered by these drugs when administered alone. ${ }^{1}$ Intensive Care Units are controlled environments where patients receive specialized and constant care. Usually patients that are admitted to an ICU are more susceptible to adverse events and drug-drug interactions due to their health instability. Along with this there is a high number of drugs prescribed which increases the probability of interactions and their severity. ${ }^{2,3,4}$ The purpose of this research is to compare two clinical decision support systems (Micromedex ${ }^{\circledR}$ and UpToDate ${ }^{\circledR}$ ) to observe if there are differences in number of Potential Drug-Drug Interactions and in how they are classified by these systems.

\section{Results and Discussion}

In this study were included patients that were over 18 years old, who stayed over 24 hours at the general adult Intensive Care Unit of the Hospital das Clínicas da Universidade Estadual de Campinas (HC-UNICAMP) and had more than one drug per medication order. Each medication order was analysed and its PDDIs were identified and classified based on the information contained in Micromedex ${ }^{\circledR}$ and UpToDate ${ }^{\circledR}$, clinical decision support systems. The data collection period was from February to May of 2015.

Six hundred, fifty seven medication orders were analysed with a mean of 12,2 drugs per medication order. Ninety one percent of the medication orders contained a PDDI.

Drug-Drug Interactions were first identified using Micromedex ${ }^{\circledR}$ as reference and later compared to the UpToDate ${ }^{\circledR}$ dabase. According to Micormedex ${ }^{\circledR}, 360$ PDDIs were identified: 15 Contra-Indicated, 159 Major and 186 Moderate. The biggest variation among the two clinical decision support systems was concerning the severity of the interactions. For example, among the 15 Contra-Indicated interactions found by Micromedex ${ }^{\circledR}$, the UpToDate ${ }^{\circledR}$ database only classified 7 of them as Contra Indicated. As for the Major severity, UpToDate ${ }^{\circledR}$ classifies about half as moderate.

Among the most occurent PDDls there are many with Metoclopramide, an antiemetic drug highly prescribed in this ICU. Another drug that is present in most of the medication orders is Dipyrone, an antinflamatory that is widely used in Brazil.

\section{Conclusions}

ICU medication orders have a large number of drugs prescribed and have many PDDIs that could cause serious adverse events. This highlights the importance of decision support systems to the health team, specially the clinical pharmacists to analyse the medication orders and discuss with the health team the best therapy. The two clinical decision support systems diverge mainly on the severity classifications of PDDIs.

Acknowledgement

The ICU multidisciplinary team and the pharmacy service at HC-UNICAMP.

The Pharmaceutical Care and Clinical Pharmacy research group.

$\mathrm{PIBIC/CNPq}$ for Sponsoring this research.

\footnotetext{
' David S Tatro PD.; Drug Interaction Facts 2013: The Authority on Drug Interactions, Lippincott Williams \& Wilkins; 2012.

${ }^{2}$ REIS,A.M.M.;CASSIANI, S.H.B. Prevalence of potential drug interactions in patients in an intensive care unit of a university hospital in Brazil. Clinical science,; v.66, n.1,p.9-15, 2011.

${ }^{3}$ KANE-GILL, S.; REA, R.S.; VERRICO, M.M; WEBER, R.J. Adverse-drug-event rates for high- cost and high-use drugs in the intensive care unit. Am J Health Syst Pharm, v.63, n.19, p.18761881, 2006.

${ }^{4}$ KANE-GILL, S. L.; JACOBI, J.; ROTHSCHILD, J. M. Adverse drug events in intensive care units: risk factors, impact, and the role of team care. Crit Care Med, v. 38, n. 6 Suppl, p. S83-9, Jun 2010.
} 